\title{
El retorno de lo ominoso: Conrad ante(s de) Freud ${ }^{1}$
}

\section{The Return of the Ominous: Conrad Before Freud}

\author{
Raúl Rodríguez \\ Pontificia Universidad Católica de Valparaíso \\ rodriguezfreire@gmail.com
}

\section{Resumen:}

El presente ensayo tiene por objetivo indagar en el vínculo que se establece entre cultura y naturaleza en dos novelas de Joseph Conrad, El corazón de las tinieblas (1902) y Nostromo (1904). Nuestro interés reside en la posibilidad de comprender tal vínculo a partir de la idea de lo ominoso (das unheimliche) que Sigmund Freud desarrollara en 1919. Lo ominoso consiste en el retorno inesperado de lo reprimido, retorno que Conrad logró comprender magistralmente en las novelas señaladas, con bastante antelación a Freud.

Palabras clave: Conrad, Freud, ominoso, naturaleza, cultura.

\begin{abstract}
:
The present essay aims to investigate the link established between culture and nature in two novels by Joseph Conrad: Heart of Darkness (1902) and Nostromo (1904). Our interest resides in the possibility of understanding this link starting from the idea of the uncanny (das unheimliche) that Sigmund Freud developed in 1919. The uncanny consists in the unexpected return of the suppressed, a return that Conrad managed to masterfully understand in these novels, anticipating Freud.
\end{abstract}

Keywords: Conrad, Freud, Uncanny, Nature, Culture.

1 El presente ensayo forma parte del proyecto postdoctoral número 3130597, financiado por Conicyt. 


\section{¡Ah, el horror! ¡El horror!}

Kurtz

\section{I}

Nostromo, la gran obra sobre América Latina escrita en inglés, comienza con la descripción de las costas de Sulaco, mirada de frente, como si se las estuviera contemplando desde el mar, como si el Capitán Józef Konrad estuviese mirando desde la proa la "exuberante [luxuriant] belleza de sus huertos de naranjos" (Conrad, Nostromo 31), quieto, sin bajar la vista, conmoviéndose con "el augusto silencio del profundo Golfo Plácido" (Conrad, Nostromo 31), aquel lugar donde "cielo, tierra y mar desaparecen juntos" (Conrad, Nostromo 34) cuando llega la noche, dándole cobijo a esa ciudad que "yace entre las montañas y la llanura, a cierta distancia, no grande, de su puerto y fuera de la línea directa de la vista desde el mar" (Conrad, Nostromo 31, 34 y 36). Imaginar así a Conrad nos recuerda a Rodrigo de Triana, el marinero que cuatro siglos antes viera por primera vez una costa que "se llamava en lengua de los indios Guanahaní", según leemos en el diario de su almirante (Colón, Los cuatro viajes 58). En este sentido, quizá no sea tan antojadiza una propuesta de lectura de Nostromo, que vincula Costaguana con Guanahani, después de todo, como Rodrigo de Triana alguna vez, Conrad también fue el primero en avistar (o inventar) una imaginaria República llamada Costaguana. Eloise Knapp ha señalado no hace mucho que Costaguana debe su nombre a las costas que avistaron por primera vez los españoles, como también al hecho de que estas costas eran llamadas por sus habitantes Guanahani; ello sumado a que "la palabra guana se refiere a un árbol amarillo que florece en la costa, lo que parece muy apropiado al fragante litoral descrito en Nostromo. También parece aceptable para los habitantes del país, ya que Conrad quiso que el nombre tuviera una asociación aborigen" (86).

Dejando de lado la costa del guano y las descripciones de la silenciosa naturaleza, el segundo capítulo nos introduce en aquello que podemos llamar las prácticas culturales de Sulaco; casas comerciales, cambios de gobierno y empresas civilizatorias se dan lugar en un par de líneas como si quisieran alborotar las páginas precedentes. Aparece la Compañía Oceánica de Navegación a Vapor y sus barcos, cuyos nombres son lo único mitológico de la novela: Juno, Saturno, Minerva, Ganímedez y Cerbero, este conocido hasta por "el indio más pobre de la aldea más recóndita" (Conrad, Nostromo 38). La compañía O.S.N., por sus siglas en inglés, ocupa un lugar relevante en la historia moderna de Sulaco, y es en ella donde se desempeña Giovanni Battista Fidanza, conocido como Nostromo (nostro uomo), el capataz de cargadores, así, en español, que es como Conrad lo escribe. Poco más adelante leemos sobre la "fuga de gobiernos y partidos derribados" (Conrad, Nostromo 39), principalmente el gobierno del dictador liberal Ribera (Ribiera, en el inglés del autor), aquel gobernante que logró atraer a los europeos, y con ellos al progreso -encarnado en el Ferrocarril Central Nacional-, hacia la lejanísima república sudamericana, pues es en parte gracias a él que Charles Gould pudo realizar en paz la explotación de la mina de 
Sulaco, y será su derrocamiento el que la exponga al peligro y la ambición de los hombres. Por otra parte, el encargado de la O.S.N., el Capitán Mitchell, que "se jactaba de conocer a fondo a los hombres y las cosas del país: cosas de Costaguana” (Conrad, Nostromo 39), es quien comienza a relatar los acontecimientos que desembocarán en aquella guerra que tendrá como resultado la independencia de Sulaco, lograda cual Panamá gracias a la ayuda estadounidense.

Como vemos en este sucinto y presuroso recuento, la pintura paisajística con que inicia Nostromo, lisa, homogénea, parece ser abruptamente intervenida por una especie de dripping conradiano, técnica que deja caer sobre ella los colores y la heterogeneidad de unas líneas que terminarán alterándola radicalmente, pues no es otra cosa que la civilización aquello que viene a interrumpir "el augusto silencio del profundo Golfo Plácido" (Conrad, Nostromo 31). Fredric Jameson lo señala de una forma muy clara en su libro Documentos de cultura, documentos de barbarie:

Nostromo, en otras palabras, no es de veras una novela sobre la insurrección política; ésta es a su vez únicamente el pretexto para el acontecimiento más fundamental de todos: la expedición de Decoud [el ideólogo de la independencia] y Nostromo a la Gran Isabel y el salvamento del tesoro, que corre parejas con la fundación de la República Occidental de Sulaco. En este nivel, no hay ningún misterio particular en cuanto a las coordenadas de conjunto de la trama [...]: la novela es un virtual ejercicio de libro de texto del dictum estructuralista de que todo relato pone en juego un paso de la Naturaleza a la Cultura. En efecto, las páginas iniciales evocan el paisaje del golfo, un paisaje sin gente; mientras que el final (excluyendo la muerte de Nostromo) celebra la sociedad acabada de la nueva república (219).

Concuerdo con que la independencia de Sulaco no corresponde al eje central de Nostromo, ya que este acontece únicamente en torno a la dicotomía naturaleza-cultura, y lo mismo podemos decir de El corazón de las tinieblas, novela sobre la que luego volveremos con cierto detalle; pero, me atrevo a señalar desde ya, la novela es más que un pasaje, pues Jameson no percibe que el paso de la naturaleza a la cultura se da a través de una determinada forma y con unas consecuencias que no escapan al deseo y al miedo que surgen cuando ambas se encuentran, por decirlo de alguna forma, frente a frente. De ahí que una lectura lévi-straussiana no permite comprender la potencia del pensamiento conradiano que aquí está en juego. Además, desde Las estructuras elementales del parentesco sabemos que para Levi-Strauss ese pasaje tiene un nombre muy determinado, incesto, y Conrad está lejos de pensar el problema que suscita la relación entre cultura y barbarie en esos términos, sobre todo porque la prohibición del incesto corresponde a un proceso mediante el cual "la naturaleza se supera a sí misma" (Levi-Strauss 59), mientras que lo que acá veremos es, por el contrario, el retorno de la naturaleza, su venganza ante la intervención civilizatoria-cultural.

Para comprender este vínculo en la obra de Conrad, tampoco podemos recurrir a la llamada antropología cultural, principalmente porque si la antropología estructural 
no nos es lo más conveniente, menos aun podría ayudarnos el modelo funcionalista (Malinowski) o el modelo primitivista (E.B. Tylor), dado que no estamos hablando de necesidades ni de supervivencias. El retorno de la naturaleza o su enseñoramiento con la cultura, más bien, se vincula con el retorno de lo primitivo, y esta sola sentencia, "retorno de lo primitivo", es suficiente para pensar el nombre más apropiado para indagar este problema: Sigmund Freud.

En un ensayo algo viejo, pero aún relevante, titulado "Las políticas contradictorias de Conrad: la ontología de la sociedad en Nostromo", Paul B. Armstrong señalaba que el "primer paso en el establecimiento de una sociedad -y en la creación del modelo de Conrad- es separar la cultura de la naturaleza" (6). Como indicamos, la novela abre con la descripción de una naturaleza exuberantemente bella, lujuriosa, nos habla del cielo, el mar y la tierra, y de las montañas que cobijan la mina de plata de los Gould, para luego presentarnos las prácticas culturales que tienen lugar en Sulaco, las mismas que vendrían a intervenir un paisaje tácito y mudo. Es en este sentido que para Armstrong, "el estado primordial de la naturaleza" -y esta es una problemática que no se restringe a Nostromo, sino prácticamente a casi toda la obra de Conrad- es "una cuestión de absoluta indiferenciación" (6), de ahí su énfasis en el silencio y la calma que la habitan, pues todo indica que para él "las diferencias no existen en la naturaleza" (6), sino en la cultura, y es esta la que le impone sus significados a aquella:

Así como la extensión de la mina transforma la sociedad de plantación y trae el ferrocarril y el telégrafo, la historia del desarrollo de Costaguana es el establecimiento creciente de diferencias que permiten medir el tiempo y el espacio, gobernar e inventariar los recursos, y distribuir rasgos culturales sobre el paisaje natural (Armstrong 6).

Conrad, por tanto, nos lleva hacia un extraño, quizá angustioso escenario cuando presenta una naturaleza silenciosa que adquiere su valor (y su función) únicamente desde la cultura; en este punto es cuando emerge "una de las primeras contradicciones ontológicas de la novela", gracias a que "retrata el valor de la plata de manera paradójica, pues al interrumpir el silencio permanente de la naturaleza, la diferenciación también introduce el cambio, la multiplicidad y la arbitrariedad de las convenciones culturales" (Armstrong 6-7).

Para Armstrong, por tanto, la mina de plata se encuentra en un cruce por el que atraviesa tanto la cultura como la naturaleza, y ello, empero, le otorga un carácter ambivalente con implicancias que van más allá de las entrevistas por este autor; es cierto que la mina consiste en una fuente natural de riquezas (y, por extensión, de poder), a la vez que su explotación obedece a una particular práctica cultural, pero lo que no se señala aquí es qué ocurre con la naturaleza cuando su silencio (silencio, claro está, otorgado culturalmente) es interrumpido. ¿¿Responde, ataca o permanece indiferente? La muerte de Nostromo, que encontramos hacia el final de la novela, nos anuncia el dictamen de una víctima. Armstrong no olvida que el valor de los metales obedece en última instancia a una convención, pero para Conrad la plata parece guardar un valor inherente, inalienable e incluso "incorruptible" y como tal es fuente de disputas: es "naturalmente inmanente 
y culturalmente contingente" (Armstrong 6). Lo cierto es que en el cruce entre cultura y naturaleza podemos encontrar algo más, en vista de que el metal precioso guarda una peligrosa potencia, aquella necesaria para despertar la pulsión reprimida en cada ser humano, pues ha permanecido oculta prácticamente desde que el hombre decidió domesticarse a sí mismo distanciándose de la naturaleza; pero esta, de vez en cuando, nos recuerda que la distancia completa es imposible, que hay momentos en los cuales el tiempo se estrecha hasta permitir el retorno de lo reprimido, y conciencia de tal acontecimiento produce una angustia capaz de un enorme e iterado grito: “ $¡ A h$, el horror! ¡El horror!”, son las últimas palabras que Kurtz pronunciara antes de fenecer. A este retorno Freud le llamó lo ominoso, algo que Conrad entrevió quizá como ningún otro escritor antes de él, anticipando incluso al autor de El malestar en la cultura.

\section{II}

Freud publicó "Lo ominoso" (Das unheimliche) en 1919, cuya aparición tiene lugar más o menos entre Tótem y tabú (1912-13) y El malestar en la cultura (1930). Lo señalo porque la presencia de ambos libros se hace notar en ese pequeño texto, lo que evidencia que se trató de un tema que le preocupó por bastante tiempo ${ }^{2}$. Extrañamente, este término casi no ha sido relacionado con la obra de Conrad, es más, hallamos solo un trabajo dedicado a El corazón de las tinieblas que realiza una lectura a partir de "Lo ominoso". A su autora, Daphna Erdinast-Vulcan, también le llama la atención esta desconsideración. En cambio, sí se ha explorado la obra conradiana a partir de cuestiones edípicas, tanto desde $\mathrm{La}$ interpretación de los sueños, como desde El Malestar en la cultura. Esta es, por ejemplo, la lectura de John Tessitore, que ha leído El corazón de las tinieblas como la disputa entre el "principio de placer" y el "principio de realidad", donde Kurtz termina cediendo a sus instintos y pasiones reprimidos por su cultura europea.

Leer a Conrad a través de Freud es una gran estrategia, pues conlleva dejar de lado la crítica que ha trabajado su obra simbólicamente, para comenzar a desentrañar la fuerte presencia psicológica de los personajes: "sugiero", dice Tessitore, "que este viaje [por el Río Congo] no es simplemente el de un autodescubrimiento por parte de Marlow, como tan a menudo se ha concluido, sino el viaje mucho mayor de toda la civilización -de su estado actual de desarrollo (europeo occidental)- hacia sus orígenes primitivos" (30). Conrad, señala luego, "usa su trabajo para examinar la civilización y sus descontentos", palabras que tienen un explícito eco de la traducción inglesa de El malestar, cuyo título original Das Unbehagen in der Kultur, fue modificado para publicarse como Civilization and Its Discontents ${ }^{3}$.

2 Las relaciones con Tótem y tabú pasan por la "omnipotencia del pensamiento". En una nota al pie de esta obra, Freud señala lo siguiente: "Parece que conferimos el carácter de lo 'ominoso' a las impresiones que corroborarían la omnipotencia de los pensamientos y el modo de pensar animista en general, en tanto que en nuestro juicio ya nos hemos extrañado de ambas creencias" (89-90).

3 Es extraño que la nota introductoria del editor resalte los problemas que se tuvo con la segunda palabra del 
En El malestar, Freud recalca la tendencia natural del hombre hacia la consecución del placer o, más bien, su tendencia a evitar el displacer provocado por las limitaciones que impone la cultura, la culpable de todos nuestros sufrimientos, ya que es ella la que impone los límites a nuestras satisfacciones. Sin embargo, la redime el hecho de que tenga por fin, a la vez, el protegernos de los sufrimientos que nos provocan nuestro cuerpo, la naturaleza y las personas que nos rodean. Con mayor frecuencia de la que desearíamos, nos pasamos la vida -señala Freud- evitando aquello que no nos produce placer, más que disfrutándolo, razón por la cual algunas veces confundimos tal evitación con el placer mismo, y terminamos por lo general conformándonos con aquella felicidad derivativa. La cultura, claro está, ha ideado unos distractores o satisfacciones sustitutivas que conocemos como ciencia, arte y drogas, pero como "es el programa del principio de placer el que fija su fin a la vida", tales sublimaciones nunca serán suficientes, dado que la economía libidinal no opera de forma estable, y además es imposible fijarla de una sola vez. De manera que para Freud "la palabra 'cultura' designa toda la suma de operaciones y normas que distancian nuestra vida de la de nuestros antepasados animales, y que sirven a dos fines: la protección del ser humano frente a la naturaleza y la regulación de los vínculos recíprocos entre los hombres" (Freud, El malestar en la cultura 88). Con naturaleza se está refiriendo a lo que rodea nuestra existencia, como también a lo que conforma nuestros cuerpos y psiquis, por lo que la conquista de la cultura consiste principalmente en la renuncia de lo pulsional. Esta disputa, entonces, es la que Tessitore ve en Kurtz, o que ve más bien entre la cultura occidental que lo ha formado y la otredad que habita en el Congo. Marlow recuerda que "su madre era medio inglesa y su padre medio francés", lo que implica que "toda Europa contribuyó en hacer de Kurtz en personaje que era” (Conrad, El corazón de las tinieblas 92), sin embargo, tras nueve años en lo más profundo de las tinieblas, trabajando en la búsqueda incesante de ese oro blanco llamado marfil, lo pulsional reprimido retornará, y lo hará para doblegar su cultura y la de su pueblo, lo que en otras palabras quiere decir que retornará para doblegar a la civilización europea misma. No hubo, en medio de la selva, paliativo alguno que lo asistiera, pues es la sublimación misma la que fue incapaz de oponerse a las fuerzas naturales, de manera que aquí la civilización terminó rendida ante los placeres que le entregó la selva. Kurtz devino así un personaje anti-civilizatorio e individualista, dado que la cultura también es nuestro vínculo con los otros iguales, pero sobre todo es nuestra defensa contra la sentencia hobbesiana: homo homini lupus.

Esta tesis de Tessitore nos parece acertada, y si bien su argumento es un poco más denso que la reducción que aquí hemos realizado, creemos haber logrado transmitir su

título, siendo que es la primera aquella que marca una importante diferencia semántica. En verdad, es extraño que el mismo Freud no distinga ambos términos, civilización y cultura, pues precisamente fue en Alemania donde por mucho tiempo se los diferenció radicalmente. Ello porque "cultura" ha estado vinculada a un proceso de desarrollo individual o interior (burgués), mientras que civilización ha obedecido a un desarrollo exterior y superficial (cortesano), lo que denota un antagonismo fuerte y claro. Freud nunca distinguió cultura de civilización, pero debe de haber conocido su diferencia, pues por algo no empleó la palabra culture en el título americano, contexto en el que la idea de cultura tenía una fuerte impronta arnoldiana, lo que la distancia de una visión que la considera represora. 
principal tesis. Y sin embargo, encontramos en él ciertas limitaciones. En primer lugar, la relación entre cultura (ley) y naturaleza (pulsión, deseo) es más compleja de lo que él ha mostrado, pues desconoce, como señaló Marcel Mauss en El sacrificio y recordó más tarde Lacan, "la relación dialéctica del deseo y de la Ley hace que nuestro deseo solo arda en una relación con la Ley” (Lacan, Seminario 738 ), es decir, la ley existe para ser transgredida y es ahí donde radica su función y su poder. Pero para nosotros hay algo más importante que no ha sido señalado, algo que podemos reconocer como una ausencia, porque la actualización de lo reprimido no opera de manera inmediata, sino que obedece a un despertar, y ese despertar se corresponde con aquello que Freud denominó lo ominoso, la forma determinada que asume el pasaje de la naturaleza a la cultura, su retorno no deliberado.

\section{III}

"Lo ominoso" es un ensayo que ha tenido bastante éxito, principalmente en el ámbito de la estética, que es de donde Freud lo toma, y lo hace no precisamente porque sea una palabra empleada en su justeza, sino porque, a su juicio, ha perdido su correcto empleo, y desea devolvérselo. Curiosamente, Freud afirma que los estetas también la han descuidado, razón por la cual resulta extraño que termine haciendo suya la definición que entrega Friedrich von Schelling, uno de los más importantes pensadores de sentimiento estético, para quien "lo ominoso es algo que, destinado a permanecer en lo oculto, ha salido a la luz" (Freud, "Lo ominoso" 224).

Freud inicia su ensayo con una revisión etimológica y lo continúa con una serie de referencias (Ernst Jentsch, Friedrich von Schiller, Ernst Theodor Amadeus Hoffmann) a los nombres que han trabajado lo ominoso de distintas formas, para cerrar con su propuesta de lectura, con su definición precisa del término. Central resulta en la primera parte de su revisión el Diccionario de la lengua alemana (Wörterbuch der deutschen Sprache), del lexicógrafo Daniel Sanders, quien le entrega variantes etimológicas y lingüísticas, y algunas traducciones (inglés, francés, español, griego, latín), lo que, revisado y contrastado, le permite encontrar la principal referencia de lo ominoso: lo familiar (Sanders 729) ${ }^{4}$, lo que hace más claro el aforismo schellingiano, que Freud ha tomado tal cual lo encontró

4 Siguiendo a Sander, Freud señala que unheimlich es, supuestamente, lo opuesto de heimlich, ya que, en una primera acepción, esta palabra tiene que ver con lo íntimo, con lo familiar (vertrau) y doméstico, con lo confiable, mientras que aquella que lleva el prefijo un vendría a ser lo desconocido, la distancia del terruño, de la casa (heim). Sin embargo, en una segunda acepción, heimlich también tiene que ver lo clandestino y secreto, con lo oculto, de manera que aquí el prefijo negativo vendría a ser lo "desasosegante, que provoca horror angustioso" (Freud, "Lo ominoso" 224), una especie de lo ominoso en sí mismo, pues es prácticamente "la marca de la represión” (Freud, "Lo ominoso" 244), y quizá por ello mismo es que sea menester mantener secreto lo que inquieta terriblemente, reprimirlo si es necesario. Heimlich, descubre entonces satisfecho Freud, es el nombre de una ambivalencia, pues "pertenece a dos círculos de representaciones que, sin ser opuestos, son ajenos entre sí: el de lo familiar y agradable, y el de lo clandestino, lo que se mantiene oculto" (Freud, "Lo ominoso" 224-5). 
en el diccionario de Sanders (quien a su vez lo ha tomado de Philosophie der Mythologie). Sanders, como lexicógrafo, lee en el libro de Schelling unos párrafos que luego sintetizará y encomillará, permitiéndole a Freud presentarnos su primer y más importante resultado:

Entonces, heimlich [familiar] es una palabra que ha desarrollado su significado siguiendo una ambivalencia hasta coincidir al fin con su opuesto, unheimlich. De algún modo, unheimlich es una variedad de heimlich. Unamos este resultado todavía no bien esclarecido con la definición que Schelling da de lo Unheimlich. La indagación detallada de los casos de lo Unheimlich \{ominoso\} nos permitirá comprender estas indicaciones (Freud, "Lo ominoso" 226).

Es importante señalar de qué tipo de variedad se trata, pues si lo familiar e íntimo es, a la vez, algo que puede llegar a coincidir con el horror, si "lo ominoso es aquella variedad de lo terrorífico que se remonta a lo consabido de antiguo, a lo familiar desde hace largo tiempo" (Freud, "Lo ominoso" 220), es porque en su base se encuentra algo muy inquietante, angustioso y ello solo puede ser debido a una sola cosa: la represión de aquello que siéndonos conocido, cercano, familiar, es mejor tener oculto: nuestros deseos y pulsiones, nuestra naturaleza, aquello que pensábamos que gracias a la cultura habíamos dominado, dejándolo atrás, en secreto. Lo ominoso es así el vehículo de una transgresión, el retorno de lo reprimido:

Parece que en nuestro desarrollo individual, todos atravesáramos una fase corres-
pondiente a ese animismo de los primitivos, y que en ninguno de nosotros hubiera
pasado sin dejar como secuela unos restos y huellas capaces de exteriorizarse; y es
como si todo cuanto hoy nos parece "ominoso" cumpliera la condición de tocar estos
restos de actividad animista e incitar su exteriorización (Freud, "Lo ominoso" 240).

Una vez que hemos descrito este término, lo que sigue es, como vemos, determinar qué provoca la exteriorización de aquello que ha permanecido por mucho tiempo oculto en lo más profundo de nuestro ser, y permite que se instale en el mundo hasta rendir la civilización. Ello porque no todo lo que ha sido reprimido es ominoso por solo el hecho de haber sufrido tal acción. Además, lo ominoso de la ficción o creación literaria, como le llama Freud, es mucho más amplio que lo ominoso del vivenciar, es más, aquel puede perfectamente incluir a este, cuyas condiciones de aparición son más simples, y sus formas menos plurales. Por ello Freud, finalmente, restringe lo ominoso a la omnipotencia de los pensamientos, al cumplimiento de los deseos, a las fuerzas que dañan secretamente $y$, por último, al retorno de los muertos. Al respecto, señala:

La condición bajo la cual nace aquí el sentimiento de lo ominoso es inequívoca. Nosotros, o nuestros ancestros primitivos, consideramos alguna vez esas posibilidades como una realidad de hecho, estuvimos convencidos de la objetividad de esos procesos. Hoy ya no creemos en ello, hemos superado esos modos de pensar, pero no nos sentimos del todo seguros de estas nuevas convicciones; las antiguas perviven en nosotros y acechan la oportunidad de corroborarse. Y tan pronto como en nuestra vida ocurre 
algo que parece aportar confirmación a esas antiguas y abandonadas convicciones, tenemos el sentimiento de lo ominoso (Freud, "Lo ominoso" 246-7).

Aquel o aquella que esté seguro de que estas experiencias animistas hayan desaparecido por completo, nada debe temer, pues lo ominoso, lo entrañable-familiar no retornará ni transgredirá ley alguna. Distinto es el caso de quienes, creyendo haber superado esas primitivas convicciones, son asaltados por algún encuentro con "esas antiguas y abandonadas convicciones" (Freud, "Lo ominoso" 247), un encuentro con la soledad, el silencio y la oscuridad, sobre todo con la soledad y el silencio de la selva, y la oscuridad de las tinieblas.

\section{IV}

La crítica anti-imperialista que Conrad realiza en Nostromo es quizá uno de sus principales y más conocidos rasgos, sobre todo porque fue uno de los primeros, si es que no el primero, en llevar esa crítica a la creación literaria. Es famoso aquel párrafo donde Holroyd, el financista estadounidense de la mina de Santo Tomé, anuncia los deseos de su país:

Cuando le llegue su hora al mayor país del universo, tomaremos la dirección de todo; industria, comercio, legislación, prensa, arte, política y religión desde el Cabo de Homos hasta el estrecho de Smith y más allá, si hay algo que valga la pena en el polo norte. Y entonces tendremos tiempo de extender nuestro predominio a todas las islas remotas y a todos los continentes del globo. Manejaremos los negocios del mundo entero, quiéralo éste o no. El mundo no puede evitarlo y nosotros tampoco, a lo que imagino (Conrad, Nostromo 101-2).

Para Edward Said, Conrad previó ejemplarmente no solo la inestabilidad de los gobiernos latinoamericanos, sino también, y de manera fundamental, "las particulares maniobras norteamericanas orientadas a crear condiciones de influencia de modo decisivo aunque apenas visible" (19), y ello con el objetivo del acaparamiento, tal como lo hicieran antes los países europeos. Conrad, por ejemplo, pone en boca del joven Decoud, quien a su vez interpreta a José Avellanos, una crítica imperialista impecable: "Las riquezas naturales de Costaguana son de importancia para la Europa del progreso... representada por audaces piratas; lo mismo que hace trescientos años el tesoro de nuestros antepasados españoles fue un tema de consideración para el resto de Europa" (Nostromo 184-5). Parece como si Conrad hubiese leído a José Martí en algún momento, si no fuera por el tono eurocéntrico que permea su discurso.

Su crítica habita la ambivalencia, pues tiene lugar única y exclusivamente bajo una mirada occidental. Chinua Achebe, por ejemplo, refiere al respecto "el deseo -aunque uno podría decir necesidad- en la psicología Occidental para situar a África como lo contrario de Europa, como un lugar de negaciones inmediatamente remotas y vagamente familiares, en comparación con el propio estado de gracia espiritual europeo" (3). Esta crítica encuentra 
eco en Edward Said, para quien Conrad es incapaz de reconocer ámbitos de resistencia subalterna, no corrompidos por Londres o Washington. Se trata de una "arrogancia paternalista" que otorga visibilidad a los nativos únicamente en virtud del reconocimiento occidental (Said 21). De lo contrario, no existen. Los únicos que tienen voz en Nostromo son los europeos, ya sean locales (criollos) o foráneos. Lo mismo ocurre en El corazón de las tinieblas, y nada lo deja más claro que unas palabras de Marlow al inicio de la novela: "La conquista del territorio, que por lo general consiste en arrebatárselo a quienes tienen una tez distinta o la nariz ligeramente más chata que la nuestra, no es nada bonita cuando la consideras con detenimiento" (Conrad, El corazón de las tinieblas 13). Hasta aquí, Conrad parece un ferviente crítico del imperialismo, cercano a Rogert Casement, quien a su juicio llevaba "una parte del alma de Las Casas en su infatigable cuerpo" (Conrad, Letters 149); pero este jamás afirmaría la sentencia con la que nuestro narrador prosigue su discurso: "Si algo la redime es solo una idea, la que la respalda" (Conrad, El corazón de las tinieblas 13). ¿Qué respalda las misiones civilizatorias en el Congo o en el Putumayo, donde Casement llevó a cabo un valiente trabajo por los derechos de los indígenas? La respuesta es clara: la occidentalización y su retórica de la inocencia, que permite exculpar la violencia cometida en nombre de la civilización, como si Europa tuviera el deber de liberar al resto de los pueblos de sí mismos (Hall). Por ello es que su obra se estructura a partir de lo que Jean Franco llamó hace un tiempo "los límites de la imaginación liberal", que ve al "resto" de Occidente sin historia, puesto que aún predomina la indiferenciada naturaleza, que permanece supuestamente vacía y silenciosa hasta que la cultura le otorga voz.

No obstante, ante tal límite de su discurso, Conrad todavía puede ofrecernos una mirada crítica de la cultura, incluyendo la misma a la que él pertenece. Si se considera la psicolectura que acá he venido desarrollando, su compresión del vínculo entre la cultura y naturaleza permite encontrar una potencia en su obra que ha permanecido inaccesible a la política crítica del imperialismo, pues Conrad nos muestra que frente a la misión civilizatoria occidentalizante, la naturaleza no permanecerá impávida, sino que reaccionará destructivamente, al encontrar en ella no una violencia desconocida, sino su complemento. Esto no quiere decir, como acertadamente ha recordado Erdinast-Vulcan "que la 'fascinación por lo abominable' sea una pieza de mero exotismo, un residuo de salvajismo que permanece en el corazón del hombre civilizado. De acuerdo al Freud de Tótem y tabú, esta se encuentra en la fundación misma de la civilización” (142). Conrad, de manera muy similar, también está señalando que lo extraño, salvaje e inquietante es inherente al hombre civilizado, y al hacerlo, develó varios años antes que Freud que lo heimlich (familiar) co-habita, si bien a veces de manera imperceptible, con lo unheimlich (siniestro), y en conjunto es que han permitido la reunión de los hombres y su devenir. Baste recordar que aquellas danzas nocturnas que se le ofrecían a Kurtz, eran poco o nada diferentes del banquete totémico de la horda primordial que funda la civilización:

[Kurtz presidió, indica Marlow,] ciertas danzas nocturnas que culminaban con ritos inclasificables, los cuales -según deduje a regañadientes de lo que oí en distintas ocasiones-, se le ofrecían a él, -¿lo entienden?-, al mismísimo señor Kurtz. Pero [su 
informe para la Sociedad Internacional para la supresión de las Costumbres Salvajes] era un escrito hermoso, una magnífica pieza literaria. Sin embargo, el párrafo inicial, a la luz de una información posterior, podría calificarse de ominoso (Conrad, El corazón de las tinieblas 93, el énfasis es nuestro).

Como el Ugolino de Dante, aquí también Conrad entrega a la ambigüedad la posibilidad del canibalismo. Sin embargo, si hemos de seguir a Freud, no deja de ser relevante la idea de que el sacrificio podría estar presente como práctica fundacional de un orden social, de todo orden social en realidad, cuya reiteración no hace más que recordarnos la violencia primigenia que requiere de una víctima necesaria (Girard). Tal develamiento es el que permite señalar que Conrad comprendió tempranamente la radical ambivalencia que atraviesa la cultura -o la civilización, ya que, como Freud, tampoco diferencia estos términos-, en cuyo interior habita lo siniestro. De manera que el autor de Nostromo y El corazón de las tinieblas nos está hablando de una cultura ominosa, construida sobre la base de múltiples represiones, las mismas que pueden retornar cuando la palabra civilizatoria es llevada allí donde no se la contempla. Recordemos otro pasaje, más claro aun, que sin nombrar lo siniestro o lo ominoso, caracteriza su revuelta contra la violencia de la cultura; un pasaje que si hubiese leído, de seguro Freud lo habría escogido como una de las mejores descripciones de aquello que él llamaba unheimiche. Poco antes de la mitad del relato, Marlow ya navega las aguas del río Congo y la imagen de Kurtz lo seduce cada vez con mayor fuerza; se encuentra "en el corazón de las tinieblas. Reinaba un gran silencio alli'”:

Éramos unos vagabundos en una tierra prehistórica [...] podríamos habernos creído los primeros hombres que tomaban posesión de una herencia maldita, condicionada al pago de una profunda angustia y esfuerzos excesivos. Pero de pronto, tras un recodo, vislumbramos paredes de junco, puntiagudos tejados de paja, un estallido de gritos, un remolido de miembros negros, una infinidad de manos aplaudiendo, de pies pataleando, de cuerpos balanceándose, de ojos girando bajo la bóveda de un pesado e inmóvil follaje. El vapor avanzaba despacio bordeando un negro e incomprensible frenesí. El hombre primitivo nos maldecía, nos adoraba, nos daba la bienvenida... ¿Quién lo sabía? Estábamos aislados, no comprendíamos nada de cuanto nos rodeaba; nos deslizábamos igual que fantasmas, maravillados y secretamente consternados, como lo estaría cualquier hombre cuerdo ante un arrebato de entusiasmo en un manicomio. No podíamos comprender porque estábamos demasiado lejos, y no podíamos recordar porque estábamos viajando en la noche de las eras primigenias, de esas que ya quedaron atrás dejando apenas señales y ningún recuerdo (Conrad, El corazón de las tinieblas 67).

Estamos en la primera parte de un largo fragmento que queremos citar, ya que a pesar de su extensión, la reflexión realizada nos obliga a revisarla completamente, puesto que nos entrega la mejor descripción de lo ominoso con que podemos contar, como si 
Conrad hubiera leído en alguno de sus viajes el aforismo de Schelling, lectura imposible por supuesto, lo que nos hace aun más admiradores de su obra, dado que aquí ya vemos aparecer los indicios de aquello que (nos) fascina en El corazón de las tinieblas: su capacidad para comprender la psiquis humana y la cultura que esta ha formado, sin saber que un médico austriaco estaba paralelamente afanado en un trabajo similar. La lectura de los sueños se emparenta, así, con la lectura de la selva, o más bien con la lectura de la cultura que la selva posibilita, porque nos permite reconocer que no hay noches ni recuerdos olvidados, sino una civilización que se ha erigido sobre ellos, porque la han fundado. De cierta manera, el viaje de Marlow es también el viaje del Ulises que retorna a su hogar, aunque en esta economía del viaje no existe la espera de una fiel Penélope, ni de un dulce Telémaco, sino la seducción de aquello, a pesar de que se nos ha enseñado ilusamente que no pertenece a nuestro tiempo, cautiva nuestra contemporánea subjetividad. Vemos, por tanto, una herencia angustiosa, y que a pesar de toda la peligrosidad que lleva a cuestas, no deja de maravillar; Marlow y sus compañeros de viaje portan la lejana civilización, pues han sido educados, como Kurtz, en Europa, y sin embargo, "la noche de las eras primigenias" permite que en ellos surja una extraña sensación, extraña y a la vez placentera, que poco a poco irán reconociendo:

\footnotetext{
La tierra parecía sobrenatural. Estamos acostumbrados a mirar la forma constreñida de un monstruo conquistado, pero allí, allí tenías ante ti una cosa monstruosa y libre. Era sobrenatural, y los hombres eran... No, no eran inhumanos. Bueno, veréis, eso era lo peor de todo, esta sospecha de que fuesen inhumanos. Te ibas dando cuenta poco a poco. Daban alaridos y brincaban, giraban y hacían muecas horribles; pero lo que te excitaba era la mera idea de su humanidad, de que fuese como la tuya, la idea de tu remoto parentesco con aquella barahúnda apasionada y salvaje. ¿Desagradable? Sí, resultaba bastante desagradable; pero si eras lo bastante hombre tenías que reconocer que había en ti un ligero rastro de respuesta a la terrible franqueza de aquel ruido, una vaga sospecha de que existía un significado que tú, tan distante de la noche de los tiempos, podías comprender ¿Y por qué no? La mente del hombre es capaz de cualquier cosa porque todo está en ella, tanto el pasado como el futuro. ¿Qué había allí, al fin y al cabo? Alegría, miedo, pesar, devoción, rabia, ¿quién sabe?, pero en cualquier caso, verdad, verdad desnuda de su capa de tiempo (Conrad, El corazón de las tinieblas 67-8).
}

El tiempo, una abstracción que incluso logra imponer una distancia ficticia -aunque efectiva materialmente- al espacio, al transformar la separación geográfica en una distancia temporal. Marlow recorre una tierra y un río primigenios y que, sin embargo, le son completamente contemporáneos, o se van haciendo contemporáneos a medida que avanza hacia el corazón de las tinieblas, hasta el punto en que el tiempo desaparece y logra encontrarse cara a cara con esa verdad que le indica que su humanidad primitiva es idéntica a su humanidad civilizada, que entre él y los negros que le rodean no hay ninguna diferencia, pues mientras el que va vestido le devela el futuro a los otros que 
van desnudos, estos le develan, como si se estuviera ante un espejo, el (su) pasado que permanece anidado en su mente, un pasado que una vez descubierto, despertado, no quedará tranquilo hasta retornar en gloria y majestad. La suerte de Kurtz es nuestro mejor ejemplo.

Lo que Conrad nos está mostrando aquí es que el intento de civilizar la naturaleza provocará la emergencia de aquello que Georg Simmel llamó, si bien para otra escena, "ruina", "la venganza de la naturaleza por la violencia que le hizo el espíritu al conformarla a su propia imagen" (182), aunque aquí esta venganza es psíquica, a diferencia de lo que está pensando Simmel, que está más preocupado de la arquitectura clásica. Sin embargo, la venganza a la que se refiere es la misma, pues la ambición de Kurtz fue respondida con toda la fuerza de la naturaleza: "Me parece que [la selva] le había susurrado cosas que desconocía acerca de él mismo, cosas que no se había planteado siquiera hasta que se asesoró con aquella enorme soledad, y el susurro había demostrado poseer un irresistible poder de fascinación" (Conrad, El corazón de las tinieblas 109).

Vemos, así, que la venganza ocurre de una forma muy determinada, pues se ajusta a aquello que Freud llamó lo ominoso, que nos vemos tentados de decir que aquí Conrad se le adelantó al padre del psicoanálisis. Lo ominoso, recordemos, es "aquella variedad de lo terrorífico que se remonta a lo consabido de antiguo, a lo familiar desde hace largo tiempo" (Freud, "Lo ominoso" 220), a aquello que la selva le recordó a Kurtz, y que es mejor tener oculto, nuestros deseos y pulsiones, nuestra familiar naturaleza, aquello que pensábamos que gracias a la civilización habíamos dejado atrás, en secreto, pero que cuando estamos en soledad con la selva, esta nos lo recuerda insistentemente, hasta el punto de no pensar en otra cosa que en saciar aquello reprimido. De ahí que lo ominoso sea el vehículo de una transgresión, un retorno posibilitado por el encuentro con aquellos objetos nombrados como incorruptibles, aunque poderosamente corruptores, como son el marfil, en el caso de Kurtz y la plata en el de Nostromo, pues mientras al primero se le reconocía como un "un genio universal" (Conrad, El corazón de las tinieblas 51), "un elegido" (47), "un emisario del progreso" (47) a cuya formación contribuyó toda Europa, y, por lo mismo, fue enviado al Congo por la Sociedad Internacional para la Supresión de los Costumbres Salvajes para que redactara un informe al respecto (cuyo primer párrafo era, en palabras de Marlow, "ominoso"), el capataz de cargadores, por su parte, era reconocido como la persona más confiable de Costaguana, "valiente entre los valientes" (Conrad, Nostromo 40), "incomparable" (49), "generoso" (147), y, también, "incorruptible" (229). Sin embargo, el marfil y la plata los hará caer en sus deseos, dado que ambos cederán a sus naturalezas, a sus pulsiones hasta terminar en la muerte. El silencio del paisaje, parece decirnos finalmente Conrad, no se debe a la pasividad de la naturaleza, sino al deseo de vivir en paz; pero cuando se la violenta, tiene la fuerza para hacernos reconocer esa verdad que cada uno guarda con su propio silencio, el mismo que terminará cediendo al horror, sí, al horror que nunca nos ha dejado solos. 


\section{Referencias}

Achebe, Chinua. “An Image of Africa: Racism in Conrad's Heart of Darkness". Hopes and Impediments. Selected Essays. New York: Anchor Books, 1990. 1-20. Medio impreso.

Armstrong, Paul B. "Conrad's Contradictory Politics: The Ontology of Society in Nostromo". Twentieth Century Literature 31.1 (1985).1-21. Medio impreso.

Colón, Cristóbal. Los cuatro viajes. Testamento. Ed. Consuelo Varela. Madrid: Alianza, 2011. Medio impreso.

Conrad, Joseph. Heart of Darkness and Selected Short Fiction. Ed. Michael Matin. New York: Barnes and Noble Classics, 2003. Medio impreso.

---. Nostromo. Trad. Olga García Arrabal. Barcelona: Verticales, 2007. Medio impreso.

---. El corazón de las tinieblas. Trad. Borja Folch. Barcelona: Ediciones B, 2007. Medio impreso.

---. Letters to R. B. Cunninghame Graham. Ed. C.T. Watts. New York: Cambridge University Press, 1969. Medio impreso.

Erdinast-Vulcan, Daphna. "Some Millennial Footnotes on Heart of Darkness".Conrad in the twenty-first century: contemporary approaches and perspectives. EdS. C.M. Kaplan, P. Lancelot Mallios y A. White. London: Routledge, 2005. 55-65. Medio impreso.

Franco, Jean. "Los límites de la imaginación liberal: Cien años de soledad y Nostromo". Revista de Crítica Literaria Latinoamericana 2.3 (1976). 69-81. Medio impreso.

Freud, Sigmund. Civilization and Its Discontents. Trad. y ed. James Strachey. New York: W.W. Norton \& Company, Inc., 1962. Medio impreso.

---. "Lo ominoso". Obras completas, vol. XVII. Trad. José L. Etcheverry. Buenos Aires: Amorrortu, 2007. 215-55. Medio impreso.

---. Tótem y tabú. Obras completas, vol. XIII. Trad. José L. Etcheverry. Buenos Aires: Amorrortu, 2007. 57-140. Medio impreso.

---. “El malestar en la cultura. Obras completas, vol. XXI. Trad. José L. Etcheverry. Buenos Aires: Amorrortu, 2007. 57-140. Medio impreso.

Girard, René. La violencia y lo sagrado. Barcelona: Anagrama, 2005. Medio impreso.

Hall, Stuart. "The Rest and the West: Discourse and Power". Formations of Modernity.S. Hall y B. Gieben, eds. Cambridge: Polity Press, 1992. 275-332. Medio impreso.

Hay, Eloise Knapp. "Nostromo". The Cambridge Companion to Joseph Conrad. Ed. J.H. Stape. Cambridge: Cambridge University Press, 1996. 81-99. Medio impreso.

Lacan, Jacques. Seminario 7. La ética del psicoanálisis. Buenos Aires: Paidós, 2009. Medio impreso.

Said, Edward. Cultura e imperialismo. Trad. Nora Catelli. Barcelona: Anagrama, 2004. Medio impreso.

Sanders, Daniel. Wörterbuch der deutschen Sprache, V.I. Leipzig: Wigand, 1876. Medio impreso.

Simmel, George. "Las ruinas". Sobre la aventura. Ensayos filosóficos. Trad. Gustau Muñoz y Salvador Mas. Barcelona: Península, 1988.181-93. Medio impreso. 
Tessitore, John. "Freud, Conrad, and 'Heart of Darkness"'. College Literature 7.1 (1980). 30-40. Medio impreso. 